\title{
Effect of pyrroloquinoline quinone disodium in female rats during gestating and lactating on reproductive performance and the intestinal barrier functions in the progeny
}

\author{
Boru Zhang, Wei Yang, Hongyun Zhang, Shiqi He, Qingwei Meng, Zhihui Chen and Anshan Shan* \\ Institute of Animal Nutrition, Northeast Agricultural University, Harbin 150030, People's Republic of China \\ (Submitted 26 September 2018 - Final revision received 21 December 2018 - Accepted 28 December 2018 - First published online 28 January 2019)
}

\section{Abstract}

The objective of this study was to investigate the effects of dietary pyrroloquinoline quinone disodium $\left(\mathrm{PQQ} \cdot \mathrm{Na}_{2}\right)$ supplementation on the reproductive performance and intestinal barrier functions of gestating and lactating female Sprague-Dawley (SD) rats and their offspring. Dietary supplementation with PQQ $\mathrm{Na}_{2}$ increased the number of implanted embryos per litter during gestation and lactation at GD 20 and increased the number of viable fetuses per litter, and the weight of uterine horns with fetuses increased at $1 \mathrm{~d}$ of newborn. The mRNA expression levels of catalase (CAT), glutathione peroxidase (GPX2), superoxide dismutase (SOD1), solute carrier family 2 member 1 (Slc2a1) and solute carrier family 2 member 3 (Slc2a3) in the placenta were increased with dietary PQQ·Na 2 supplementation. Dietary supplementation with PQQ $\cdot \mathrm{Na}_{2}$ in gestating and lactating rats increased the CAT, SOD and GPx activities of the jejunal mucosa of weaned rats on PD 21. Dietary supplementation with PQQ $\cdot \mathrm{Na}_{2}$ in female rats affected the expression of tight junction proteins (claudin, zonula occludens-1 (ZO-1) and occludin) in the jejunal mucosa of their offspring by increasing the expression of ZO-1 mRNA in the expression of ZO-1 and claudin mRNA in the jejunal mucosa of weaned rats on PD 21. In conclusion, dietary supplementation with PQQ· $\mathrm{Na}_{2}$ in gestating and lactating female rats had positive effects on their reproductive performance and on the intestinal barrier of weaned rats.

\section{Key words: Pyrroloquinoline quinone: Pyrroloquinoline quinone disodium: Reproductive performance: Oxidative stress:} Intestinal barrier

Pyrroloquinoline quinone (PQQ) (4,5-dihydro,5-dioxo $H$-pyrroloquinoline-2,7,9 tricarboxylic acid) is a three-cyclic helobacterium that acts as a substitute for the role of combined oxidative agents of many bacterial hydrogen derivatives including methanol, ethanol and glucose dehydrogenases ${ }^{(1,2)}$ also called methotaxin ${ }^{(3,4)}$. PQQ, which is a water-soluble, thermo-stable TAG-quinone, is widely distributed in nature ${ }^{(5)}$ and characterised as a mammalian vitamin-like redox cofactor $^{(6)}$. Its reducing properties are good candidates for redox control signalling in viable cells ${ }^{(7)}$ and are more effective than other bioactive quinones and ascorbic acid ${ }^{(8)}$. PQQ has powerful antioxidant properties and is found naturally in plant tissues, mammalian organs and biological fluids ${ }^{(9)}$. The antioxidant action of PQQ depends on its ability to catalyse the conversion of superoxide to dioxy. Furthermore, PQQ in oxidised quinone form is reduced to its semi-quinone and hydroquinone forms; and, under appropriate conditions, PQQ can catalyse a continuous redox cycle ${ }^{(10)}$. The potential number of catalyst cycles is approximately 2000, and four catalytic cycles of ascorbic acid have been reported ${ }^{(5)}$. Due to its antioxidant properties $^{(11)}$, PQQ further exerts a neuroprotective and peritoneal protective action against mammalian oxidative stress $^{(12)}$.

PQQ is ubiquitous in nature and found in many dietary sources such as fermented soyabeans, tea, green peppers, parsley, kiwi and human milk ${ }^{(13,14)}$. However, according to various reports, the PQQ content in food differs even though various PQQ instrumental analysis and bioassay methods have been established. This is because PQQ is chemically reactive and easily forms derivatives or condensation products with other nutrients $^{(15,16)}$. Although PQQ is not currently classified as a vitamin, PQQ has been implicated as an important nutrient in mammals ${ }^{(17)}$. However, PQQ has attracted considerable attention, as it is important for mammalian growth, development, reproduction and immune function. PQQ is also beneficial to animal growth and development ${ }^{(18)}$. Current research indicates that mice fed a well-nourished diet but lacks PQQ exhibit decreases in the fertility of both first- and second-generation

Abbreviations: CAT, catalase; E2, oestradiol; GD, gestation day; GPx, glutathione peroxidase; LH, luteinising hormone; PD, postnatal day; PQQ, pyrroloquinoline quinone; PQQ $\mathrm{Na}_{2}$, pyrroloquinoline quinone disodium; PRG, progesterone; ROS, reactive oxygen species; Slc2a1, solute carrier family 2 member 1; Slc2a3, solute carrier family 2 member 3; SOD, superoxide dismutase; ZO-1, zonula occludens-1. 
mice and in the growth rate of newborns when compared with mice supplemented with $\mathrm{PQQ}^{(19)}$. Signs of pregnancy and neonatal PQQ deprivation in severely affected mice usually include friable skin and a humpback posture ${ }^{(20)}$.

In Canada, PQQ-containing products have been approved for use as natural antioxidants for health maintenance ${ }^{(21)}$ and in the United States as a dietary supplement for human consumption (e.g. BioPQQ). The most widely used commercial product is pyrroloquinoline quinone disodium (PQQ $\cdot \mathrm{Na}_{2}$ ) salt ${ }^{(22)}$. PQQ $\mathrm{Na}_{2}$ is generally used in various experiments due to its high solubility in water ${ }^{\text {(23) }}$, which makes it easy to handle, and this property gives PQQ $\cdot \mathrm{Na}_{2}$ an advantage in comparison with free-form PQQ ${ }^{(24)}$. Although PQQ is not biosynthesised in mammals, trace amounts of PQQ have been found in human and rat tissues due to its wide distribution across dietary sources. Nutritional studies in rodents have revealed that a PQQ deficiency exhibits diverse systemic responses, including growth impairment, immune dysfunction and abnormal reproductive performance. However, it is still unknown whether PQQ increases reproduction performance or not. In addition, there are no published data on the effects of maternal dietary treatment and PQQ on the intestinal functioning of their offspring. Therefore, the objective of the present study was to determine whether dietary PQQ $\cdot \mathrm{Na}_{2}$ supplementation is able to increase the number of viable fetuses per litter, and whether the weight of uterine horns with fetuses increased at $1 \mathrm{~d}$ of newborn. We also explored whether dietary PQQ $\mathrm{Na}_{2}$ supplementation was able to improve the antioxidant capacity of the small intestine and the intestinal morphology of weaned rats. In summary, the results of this study could lay a foundation for the further effects of PQQ on maternal reproductive performance and intestinal health.

\section{Methods}

\section{Ethics statement}

This study was performed in strict accordance with the recommendations of the National Research Council Guide, and all animal experimental procedures were approved by the Ethical and Animal Welfare Committee of Heilongjiang Province, China. All surgeries were performed under anaesthesia using an intraperitoneal injection of sodium pentobarbital, and every effort was made to minimise animal suffering.

\section{Animals and experimental design}

Pregnant rats received diets containing different concentrations of PQQ $\cdot \mathrm{Na}_{2}$ (purity, $\geq 99 \cdot 5 \%$ ). The rats were divided into five groups and received a daily feeding of $0,0.2,0.4,0.8$ and $1.6 \mathrm{mg} / \mathrm{kg}$ of PQQ $\cdot \mathrm{Na}_{2}$, respectively (Table 1 ). The animals were given drinking water and food ad libitum.

Sprague-Dawley (SD) rats were obtained from the Jilin University Laboratory Animal Centre (Changchun, China) and were acclimated for 1 week before experimentation. The weights of the male rats ranged from 300 to $325 \mathrm{~g}$, and the weights of the female rats ranged from 190 to $210 \mathrm{~g}$ (at 9 weeks). The experiment was conducted on 120 female rats
Table 1. Composition and nutrient levels of the basal diet (air-dry basis)

\begin{tabular}{lr}
\hline Item & \multicolumn{1}{c}{$\%$} \\
\hline Maize starch & 41.65 \\
Dextrin starch & 13.20 \\
Casein & 20.00 \\
Soyabean oil & 6.00 \\
Cellulose & 5.00 \\
Cane sugar & 10.00 \\
L-Cys $_{\text {CaHPO }}$ & 0.30 \\
Limestone $_{\text {Choline }}$ & 0.80 \\
Premix & 1.30 \\
Total & 0.25 \\
\end{tabular}

* The premix provided the following per $\mathrm{kg}$ of the diet: Fe (as ferrous sulfate) $35 \mathrm{mg}$, $\mathrm{Cu}$ (as copper sulphate) $6 \mathrm{mg}, \mathrm{Zn}$ (as zinc sulphate) $30 \mathrm{mg}, \mathrm{Mn} 10 \mathrm{mg}$, vitamin A $4.2 \mathrm{mg}$, vitamin $D_{3} 0.037 \mathrm{mg}$, vitamin $E 80 \mathrm{mg}$, riboflavin $12 \mathrm{mg}$, nicotinic acid $60 \mathrm{mg}$, D-pantothenic acid $24 \mathrm{mg}$, vitamin $\mathrm{B}_{12} 1.2 \mathrm{mg}$, biotin $0.2 \mathrm{mg}$.

Table 2. Pyrroloquinoline quinone disodium (PQQ $\left.\cdot \mathrm{Na}_{2}\right)$ concentrations in feed and the number of rats treated per concentration group

\begin{tabular}{lcc}
\hline Experimental group & $\begin{array}{c}\mathrm{PQQ} \cdot \mathrm{Na}_{2} \text { supplementation } \\
(\mathrm{mg} / \mathrm{kg})\end{array}$ & Number of rats \\
\hline PQQ 0 (control) & 0 & 24 \\
PQQ 0.2 & 0.2 & 24 \\
PQQ 0.4 & 0.4 & 24 \\
PQQ 0.8 & 0.8 & 24 \\
PQQ 1.6 & 1.6 & 24 \\
\hline
\end{tabular}

divided into five groups that received a daily feeding of $0,0 \cdot 2$, $0.4,0.8$ and $1.6 \mathrm{mg} / \mathrm{kg}$ of PQQ. $\mathrm{Na}_{2}$. Male rats were used as sires only and were not treated. The rats were kept in plastic rat cages and had free access to food and water. The animals were maintained on a $12 \mathrm{~h}$ light $-12 \mathrm{~h}$ dark cycle at $24 \pm 2^{\circ} \mathrm{C}$ in the study room. The relative humidity was maintained at $47-$ $55 \%{ }^{(25,26)}$. Throughout the study, the male and female rats were fed experimental animal rations (University Laboratory Animal Centre). The feed was prepared in an experimental feed mill using high-precision mixers, and all the feedstuffs were subjected to post-processing analytical control. The groupings are presented in Table 2.

Cohabitation began at approximately 16.30 hours on each mating day (two females per male). The next morning, each female was examined for the presence of sperm using a vaginal lavage. A total of 120 sperm-positive females were presumed to be pregnant on gestational day (GD) 0 , and a stratified random procedure was used to assign each animal to a control group or one of the four treatment groups ${ }^{(26)}$. Each pregnant rat was individually maintained in a polycarbonate metabolic cage (Tecniplast). The diet was maintained until rats were weaned on postnatal day (PD) 21. A total of eight pregnant rats within each group were euthanised on GD 20. A total of eight weaning rats per group were euthanised at the time of weaning on PD 21.

\section{Caesarean section, slaughter and collection of samples}

The animals were euthanised under anaesthesia using an intraperitoneal injection of sodium pentobarbital $(0.5 \mathrm{ml} / \mathrm{kg})$ on 
GD 20. For blood collection, microcentrifuge tubes were coated with $10 \mathrm{ml}$ of heparin sodium salt $(20 \mathrm{U} / \mathrm{ml}$ in phosphate buffered saline). Whole blood was collected from the submandibular site as described previously and maintained on ice for $30 \mathrm{~min}$. The samples were centrifuged at $3000 \mathrm{~g}$ and $4^{\circ} \mathrm{C}$ for $10 \mathrm{~min}$. The plasma layers were removed, placed into sterile microcentrifuge tubes, and stored at $-40^{\circ} \mathrm{C}$ until assayed. The placentas were frozen in liquid $\mathrm{N}_{2}$, stored at $-80^{\circ} \mathrm{C}$ and either subjected to RNA or quantitative RT-PCR to analyse their gene expressions. The remaining pregnant rats were fed with the experimental diet until the pups were weaned at 3 weeks of age. A total of eight weaned rats with similar body weights were randomly selected from each group and killed using diethyl ether anaesthetisation. After a laparotomy, their small intestines were dissected and freed from the mesenteric attachment, and all chyme were removed immediately. The jejunum segments were rinsed in a chilled sodium chloride solution $(0.9 \mathrm{~g} / \mathrm{l}$ saline $)$ and divided into three segments of equal length. One part was frozen in liquid $\mathrm{N}_{2}$ and stored at $-80^{\circ} \mathrm{C}$ until RNA extraction. The second part was fixed in $10 \%$ formalin for morphological analysis. The third part was sealed into pockets and preserved at $-20^{\circ} \mathrm{C}$ until used for the evaluation of antioxidant status. The contents of the caecum were immediately frozen in liquid $\mathrm{N}_{2}$ and stored at $-80^{\circ} \mathrm{C}$ until microbial DNA analysis.

\section{Evaluation of antioxidant enzyme activity}

The activities of total superoxide dismutase (SOD), glutathione peroxidase (GPx) and catalase (CAT) were analysed using commercial reagent kits ${ }^{(27)}$. Analysis of the SOD activity was based on the SOD-mediated inhibition of the formation of nitrite from hydroxylammonium in the presence of $\mathrm{O}^{2-}$ generators (xanthine/xanthine oxidase) ${ }^{(28)}$. Activity of SOD was expressed as units/mg of protein and determined by measuring the reduction in the optical density of the reaction solution at $550 \mathrm{~nm}$. GPx is an enzyme that catalyses glutathione oxidation by oxidising the reduced tripeptide GSH into GSSG ${ }^{(29)}$. GPx activity was expressed as units/mg of protein, and one unit was defined as the amount required to decrease GSH by $1 \mathrm{~mm} / \mathrm{min}$ after subtracting the decrease in $\mathrm{GSH} / \mathrm{min}$ obtained from the non-enzymatic reaction. CAT activity was assayed by the method developed by Aebi ${ }^{(30)}$ and calculated as nmol $\mathrm{H}_{2} \mathrm{O}_{2}$ consumed/min per $\mathrm{mg}$ of tissue protein. Approximately $1 \mathrm{~g}$ of mucosal scrapings was homogenised after being suspended in $9 \mathrm{ml}$ of saline. After centrifugation at $3000 \mathrm{rpm}$ for $15 \mathrm{~min}$, the supernatant was taken for the measurement of the total SOD, reduced GSH, MDA and CAT. All antioxidant parameters were measured using the methodology of assay kits supplied by Nanjing Jiancheng Bioengineering Institute ${ }^{(31,32)}$.

\section{Real time-PCR (RT-PCR)}

Total DNA from the middle section of the caecum samples was extracted using the TIANamp Stool DNA Kit (Tiangen Biotech Ltd), according to the manufacturer's instructions. The quantity and quality of DNA were assessed using a NanoPhotometerP330 spectrophotometer (Implen GmbH). Primers for total eubacteria, Lactobacillus spp., Enterobacteriaceae and bifidobacteria spp. were designed according to previously published data $^{(33,34)}$. Primers (Table 3) were used for the estimation of select bacterial groups by quantitative real-time PCR using the ABI 7500 Real-Time PCR system (Applied Biosystems Limited). For bacterial groups, real-time PCR used the SYBR ${ }^{\circledR}$ Premix Ex $\mathrm{Taq}^{\mathrm{TM}}$ II system (TaKaRa ${ }^{\oplus}$ Bio Catalog). The PCR was run in a volume of $20 \mu \mathrm{l}$, with $10 \mu \mathrm{l}$ of $\mathrm{SYBR}^{\circledast}$ Premix Ex Taq ${ }^{\mathrm{TM}}, 0 \cdot 8 \mu \mathrm{l}$ of each primer $(0.4 \mu \mathrm{m}), 0 \cdot 4 \mu \mathrm{l}$ of ROX Reference Dye II (TaKaRa), $6 \cdot 0 \mu \mathrm{l}$ of double-distilled water and $2 \mu \mathrm{l}$ of DNA template. The thermal cycling conditions involved an initial denaturation step at $95^{\circ} \mathrm{C}$ for $5 \mathrm{~min}$, followed by forty cycles of $95^{\circ} \mathrm{C}$ for $15 \mathrm{~s}$ and $72^{\circ} \mathrm{C}$ for $30 \mathrm{~s}$. Dissociation analyses of the PCR products were carried out to confirm the specificity of the resulting PCR products. Quantification was performed in duplicate, and the mean values were calculated. The results were reported as $\log _{10} 16 \mathrm{~S}$ ribosomal DNA gene copies per gram fresh matter.

Total RNA was extracted from approximately $100 \mathrm{mg}$ of frozen jejunal tissues. The concentration of RNA was estimated based on its absorbance at $260 \mathrm{~nm}$, which was determined using a spectrophotometer. The RNA quality was determined by checking its integrity through agarose gel electrophoresis and by confirming that the $A_{260 \mathrm{~nm}}: A_{280 \mathrm{~nm}}$ absorbance ratio was between 1.8 and $2 \cdot 0$. Total RNA from each sample was converted into complementary DNA using the Prime Script ${ }^{\circledast}$ RT reagent kit $\left(\mathrm{TaKaRa}^{\circledast}\right.$ Bio Catalog) according to the manufacturer's instructions and used for RT-PCR. $\beta$-Actin was used as a reference gene and was stable and not changed by the different treatments. The real-time PCR process was in accordance

Table 3. Primers used for real-time PCR to detect bacterial numbers

\begin{tabular}{llc}
\hline Targeted bacterial group (amplicon size) & Primer sequence $\left(5^{\prime}-3^{\prime}\right)$ & Annealing temperature $\left({ }^{\circ} \mathrm{C}\right)$ \\
\hline Total eubacteria (200 bp) & F: CGGYCCAGACTCCTACGGG & 58 \\
& R: TTACCGCGGCTGCTGGCAC & 62 \\
\hline Lactobacillus spp. (341 bp) & F: AGCAGTAGGGAATCTTCCA & 60 \\
Enterobacteriaceae (195 bp) & R: CACCGCTACACATGGAG & 60 \\
Bifidobacteria spp. $(243 \mathrm{bp})$ & F:CATTGACGTTACCCGCAGAAGAAGC & 58 \\
& R: CTCTACGAGACTCAAGCTTGC & \\
& F: CCACATCCAGC(A/G)TCCAC & \\
\hline
\end{tabular}

$F$, forward; R, reverse. 
Table 4. Primers used for real-time PCR

\begin{tabular}{|c|c|c|c|}
\hline Genes & Primer sequence $\left(5^{\prime}-3^{\prime}\right)$ & Product size (bp) & GenBank no. \\
\hline$I L-1 \beta$ & $\begin{array}{l}\text { F: GCCAACAAGTGGTATTCTCCA } \\
\text { R: TGCCGTCTTTCATCACACAG }\end{array}$ & 120 & NM-031512.2 \\
\hline IL-1a & $\begin{array}{l}\text { F:GAGTCGGCAAAGAAATCAAGA } \\
\text { R:TTCAGAGACAGATGGTCAATGG }\end{array}$ & 112 & NM_017019.1 \\
\hline IL-6 & $\begin{array}{l}\text { F: AGTTGCCTTCTTGGGACTGA } \\
\text { R: ACTGGTCTGTTGTGGGTGGT }\end{array}$ & 102 & NM_012589.2 \\
\hline IL-8 & $\begin{array}{l}\text { F: AAGAGGGCTGAGAACCAAGA } \\
\text { R:CCCACACAATACACAAAGAACTG }\end{array}$ & 124 & XM_004833923.1 \\
\hline$T N F-a$ & $\begin{array}{l}\text { F: TTCCGTCCCTCTCATACACTG } \\
\text { R: AGACACCGCCTGGAGTTCT }\end{array}$ & 149 & NM_012675.3 \\
\hline Occludin & $\begin{array}{l}\text { F: CTCCAACGGCAAAGTGAATG } \\
\text { R: CGGACAAGGTCAGAGGAATC }\end{array}$ & 104 & NM_031329.2 \\
\hline Claudin & $\begin{array}{l}\text { F: CTGCCTGGAGTCTTGGTGTC } \\
\text { R: GAGGGTAGGTGGGTGGGTAA }\end{array}$ & 122 & NM_001012022.1 \\
\hline$Z O-1$ & $\begin{array}{l}\text { F: AGCTGCCTCTCAACAGAAAG } \\
\text { R: GTCTCTGGGCACTGTGTGAG }\end{array}$ & 217 & NM_001106266.1 \\
\hline Slc2a1 & $\begin{array}{l}\text { F: CCAGATACCTACCGGTTA } \\
\text { R: TCCTTTAACTGCAGCTGA }\end{array}$ & 145 & NM_138827.1 \\
\hline Slc2a3 & $\begin{array}{l}\text { F: CTGAAATGGAAAGGGTGT } \\
\text { R: CCATGCTTACACACAAGC }\end{array}$ & 112 & NM_017102.2 \\
\hline$G P x 2$ & $\begin{array}{l}\text { F: CCGTGCTGATTGAGAATGTG } \\
\text { R: AGGGAAGCCGAGAACCACTA }\end{array}$ & 113 & NM_183403.2 \\
\hline CAT & $\begin{array}{l}\text { F:CGTCACTCAGGTGCGGACATTC } \\
\text { R:TCAGGTGGTTGGCAATGTTCTCAC }\end{array}$ & 124 & NM_012520.2 \\
\hline SOD1 & $\begin{array}{l}\text { F:GGCTGTACCAGTGCAGGTCCTC } \\
\text { R: CCACCAGTGTGCGGCCAATG }\end{array}$ & 131 & NM_000454.4 \\
\hline HO1 & $\begin{array}{l}\text { F:TATCGTGCTCGCATGAACACTCTG } \\
\text { R:GTTGAGCAGGAAGGCGGTCTTAG }\end{array}$ & 90 & NM_012580.2 \\
\hline$\beta$-Actin & $\begin{array}{l}\text { F: ACCCGCGAGTACAACCTTC } \\
\text { R: CCCATACCCACCATCACACC }\end{array}$ & 207 & NM_031144 \\
\hline
\end{tabular}

F, forward; R, reverse; ZO-1, zonula occludens-1; SIc2a1, solute carrier family 2 member 1; SIc2a3, solute carrier family 2 member 3 ; GPX, glutathione peroxidase; CAT, catalase; $S O D$, superoxide dismutase; HO1, haem oxygenase 1.

with the description in a previous study. All the PCR were performed in triplicate (Table 4). The relative gene expression levels in the intestines and placenta were determined using the $2^{-\Delta \Delta C_{\mathrm{t}}} \operatorname{method}^{(35)}$.

\section{Morphological analysis and brush border enzyme activities}

Cross-sectional jejunal samples from the formalin-preserved segments were cut into $2 \mathrm{~mm}$ sections and fixed by standard paraffin embedding. Samples were sectioned at $5 \mathrm{~mm}$ and stained with haematoxylin-eosin. Each slide was divided into three single segments and the microstructures of the jejunum were analysed using an optical microscope (Nikon Eclipse E400). The villous heights and crypt depths of thirty randomly chosen villi were measured.

Other sections $(10 \mathrm{~cm})$ of jejunum were dissected from each rat and rinsed with PBS with a $\mathrm{pH}$ of $7 \cdot 2$ to measure the specific activity of mucosa enzymes. The mucosa was carefully scraped off with a glass slide placed in Eppendorf tubes and immediately frozen in liquid $\mathrm{N}_{2}$ for later measurement. Mucosa samples were thawed and flushed with isotonic saline at $4{ }^{\circ} \mathrm{C}$. Exactly $0.5 \mathrm{~g}$ of mucosa was homogenised for $2 \mathrm{~min}$ in a chilled sodium chloride solution $(0.9 \mathrm{~g} / \mathrm{l}$ saline) with the ratio $1: 9(\mathrm{w} / \mathrm{v})$, followed by centrifugation at $3000 \mathrm{rpm}$ for $10 \mathrm{~min}$. The supernatant was diluted with a sodium chloride solution $(0.9 \mathrm{~g} / \mathrm{l}$ saline $)$ at a ratio of
$1: 5(\mathrm{w} / \mathrm{w})$ for the determination of lactase ( $\beta$-galactosidase; $E C$ 3.2.1.23) and sucrase (sucrose- $\alpha$-glucosidase; EC 3.2.1.48) activities and later diluted 1:50 (w/w) for the determination of maltase ( $\beta$-glucosidase; EC 3.2.1.20).

\section{Hormone levels}

The levels of prolactin (PRO), follicle-stimulating hormone (FSH), luteinising hormone (LH), progesterone (PRG) and oestradiol (E2) were determined using an ELISA kit (R\&D Systems Inc.), according to the manufacturer's recommended protocol.

\section{Statistical analysis}

All data were analysed using SPSS 19.0 software (SPSS Inc.). All data were analysed using the one-way ANOVA, and means were compared using Duncan's multiple range test. A Shapiro-Wilk $W$ normality test was performed. All pairwise multiple comparisons of means test for determining significance of differences among the five treatment groups were performed as applicable. The individual rat and her litter were used as the experimental unit. The results were presented as mean values and the standard error of the mean. In all statistical tests used, $P<0.05$ was considered statistically different. 
Table 5. Effects of dietary pyrroloquinoline quinone (PQQ) disodium supplementation during gestation and lactation on reproductive performance of rats (Mean values with their standard errors)

\begin{tabular}{|c|c|c|c|c|c|c|}
\hline Item & PQQ 0 & PQQ 0.2 & PQQ 0.4 & PQQ 0.8 & PQQ 1.6 & SEM \\
\hline \multicolumn{7}{|l|}{$20 \mathrm{~d}$ of gestation } \\
\hline Number of implanted embryos per litter & $11 \cdot 83^{b}$ & $12 \cdot 33^{a, b}$ & $13 \cdot 17^{\mathrm{a}, \mathrm{b}}$ & $13 \cdot 50^{\mathrm{a}}$ & $13 \cdot 67^{\mathrm{a}}$ & 0.24 \\
\hline Placental wet weights $(\mathrm{g})$ & 1.42 & 1.51 & 1.64 & 1.65 & 1.72 & 0.11 \\
\hline Weight of uterine horn with fetuses $(\mathrm{g})$ & 81.94 & $82 \cdot 39$ & $86 \cdot 02$ & $89 \cdot 18$ & $96 \cdot 10$ & $2 \cdot 52$ \\
\hline Length of uterine horn with fetuses $(\mathrm{cm})$ & 23.50 & $26 \cdot 25$ & 31.00 & $32 \cdot 17$ & $32 \cdot 83$ & $1 \cdot 34$ \\
\hline \multicolumn{7}{|l|}{$1 \mathrm{~d}$ of newborn } \\
\hline Number of viable fetuses per litter & $11 \cdot 50^{\mathrm{b}}$ & $12 \cdot 33^{a, b}$ & $12 \cdot 50^{\mathrm{a}, \mathrm{b}}$ & $13 \cdot 17^{\mathrm{a}, \mathrm{b}}$ & $13 \cdot 67^{\mathrm{a}}$ & 0.23 \\
\hline Born alive litter weight (g) & $83.51^{\mathrm{b}}$ & $84.93^{a, b}$ & $87 \cdot 27^{a, b}$ & $95 \cdot 58^{a, b}$ & $100 \cdot 39^{a}$ & $3 \cdot 27$ \\
\hline \multicolumn{7}{|l|}{$21 \mathrm{~d}$ of lactation (weaned rats) } \\
\hline Number of viable fetuses per litter & $10 \cdot 17$ & $10 \cdot 33$ & $10 \cdot 67$ & $11 \cdot 17$ & 11.33 & 0.21 \\
\hline Litter weaning weight $(\mathrm{g})$ & 594.41 & $605 \cdot 32$ & $605 \cdot 60$ & $616 \cdot 47$ & $618 \cdot 82$ & 13.04 \\
\hline
\end{tabular}

${ }^{\mathrm{a}, \mathrm{b}}$ Mean values within a row with unlike superscript letters were significantly different $(P<0.05)$.
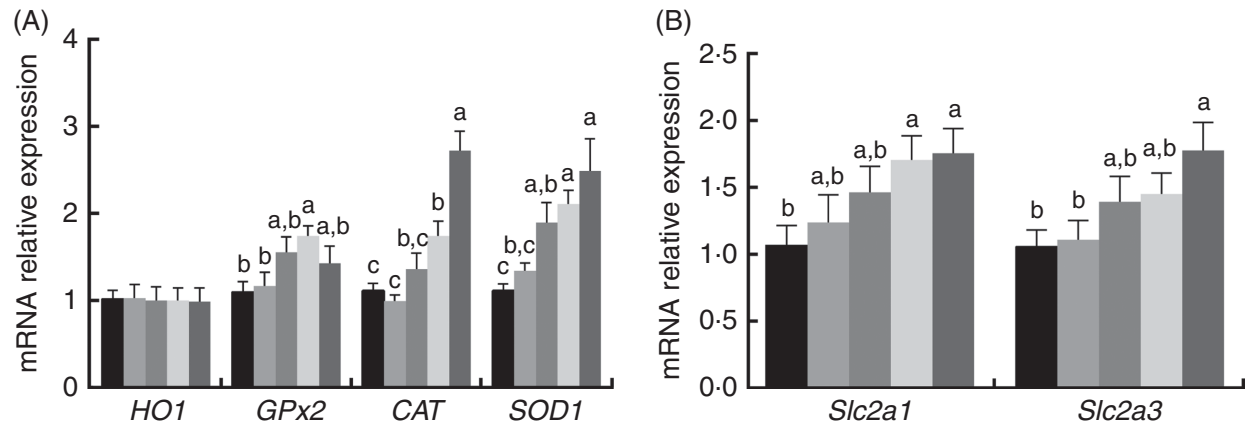

Fig. 1. Effects of dietary pyrroloquinoline quinone (PQQ) disodium supplementation during gestation and lactation of rats on antioxidant status and glucose transporter in placentas for real-time PCR of female rats. (A) Haem oxygenase 1 (HO1), glutathione peroxidase (GPx2), catalase (CAT), superoxide dismutase (SOD1) and $(B)$ quantitative mRNA expression of solute carrier family 2 member 1 (Slc2a1) and solute carrier family 2 member 3 (S/c2a3) by real-time PCR in rat placentas. Values are means $(n 6)$, with their standard errors represented by vertical bars. ${ }^{\text {a,b,c }}$ Mean values with unlike letters were significantly different $(P<0.05)$. $\square, P Q Q 0$; PQQ 0.2; , $P Q Q 0.4 ;$, , PQQ 0.8; , $P Q Q 1.6$.

\section{Results}

\section{Reproductive performance}

The results pertaining to the reproductive performance of gestational rats are shown in Table 5. The placental wet weights and the weight and length of uterine horns with fetuses at GD 20 in female rats exhibited an increasing tendency, but this difference was not significant $(P>0.05)$. The number of implanted embryos per litter increased significantly $(P<0.05)$ with dietary 0.8 and $1.6 \mathrm{mg} / \mathrm{kg}$ PQQ $\cdot \mathrm{Na}_{2}$ during gestation and lactation at GD 20, showing dose dependency. The number of viable fetuses per litter and born alive litter weight increased at $1 \mathrm{~d}$ of newborn $(P<0.05)$ with dietary $1.6 \mathrm{mg} / \mathrm{kg}$ PQQ $\cdot \mathrm{Na}_{2}$, in a dose-dependent manner, compared with the control. However, weaned rats did not show any effects on these variables with dietary PQQ $\mathrm{Na}_{2}$ supplementation during gestation and lactation $(P>0.05)$.

\section{Placental antioxidant and glucose transporter gene expression}

The mRNA expression levels of antioxidant and glucose transporter genes are presented in Fig. 1. The mRNA expression levels of CAT, GPX2 and SOD1 in the placenta increased $(P<0.05)$ with dietary 0.8 and $1.6 \mathrm{mg} / \mathrm{kg} \quad \mathrm{PQQ} \cdot \mathrm{Na}_{2}$ supplementation, but the mRNA expression levels of haem oxygenase 1 were not affected $(P>0.05)$. In addition, the mRNA expression of solute carrier family 2 member 1 (Slc2a1) and solute carrier family 2 member 3 (Slc2a3) were also increased $(P<0.05)$ with dietary $1.6 \mathrm{mg} / \mathrm{kg} \mathrm{PQQ} \cdot \mathrm{Na}_{2}$, in a dose-dependent manner.

Concentrations of follicle-stimulating hormone, luteinising hormone, prolactin, progesterone and oestradiol in the plasma of female rats at gestation day 20

The gonadotropin (FSH, LH and PRO) and sex steroid (PRG and E2) concentrations in blood plasma obtained during caesarean section on GD 20 are shown in Table 6. The E2 and PRG concentrations were significantly increased $(P<0.05)$ with dietary PQQ $\cdot \mathrm{Na}_{2}$, and this is the response at all concentrations. The concentration of LH was significantly increased $(P<0.05)$ for the PQQ 0.4 and PQQ 1.6 groups, while the concentration of PRO increased significantly $(P<0.05)$ for the PQQ 0.8 and PQQ $1 \cdot 6$ groups.

\section{Intestinal morphology of weaned rats}

The effects of dietary PQQ $\mathrm{Na}_{2}$ supplementation during gestation and lactation on villous height, crypt depth and villous 
Table 6. Concentrations of follicle-stimulating hormone (FSH), luteinising hormone (LH), prolactin (PRO) and oestradiol (E2) in the plasma of female rats on gestation day 20

(Mean values with their standard errors, $n 6$ )

\begin{tabular}{|c|c|c|c|c|c|c|}
\hline Item & PQQ 0 & PQQ 0.2 & PQQ 0.4 & PQQ 0.8 & PQQ 1.6 & SEM \\
\hline E2 (pmol/l) & $185 \cdot 76^{\mathrm{b}}$ & $247 \cdot 26^{a}$ & $230 \cdot 84^{a}$ & $249 \cdot 31^{a}$ & $221.46^{a}$ & 4.08 \\
\hline $\mathrm{LH}(\mathrm{pg} / \mathrm{ml})$ & $2231.92^{b}$ & $1986 \cdot 50^{b}$ & $2683.03^{a}$ & $2369 \cdot 39^{a, b}$ & $2646 \cdot 38^{a}$ & 51.89 \\
\hline $\mathrm{FSH}(\mathrm{U} / \mathrm{l})$ & 16.98 & $17 \cdot 40$ & 17.57 & $17 \cdot 64$ & $18 \cdot 14$ & 1.27 \\
\hline PRO (ng/l) & $432 \cdot 13^{b}$ & $488.54^{b}$ & $473 \cdot 15^{b}$ & $574.79^{a}$ & $575 \cdot 95^{\mathrm{a}}$ & 66.39 \\
\hline PRG (pmol/l) & $2568 \cdot 29^{b}$ & $3445 \cdot 12^{\mathrm{a}}$ & $3261.56^{\mathrm{a}}$ & $3458.32^{\mathrm{a}}$ & $3607.53^{a}$ & $66 \cdot 14$ \\
\hline
\end{tabular}

$\mathrm{PQQ}$, pyrroloquinoline quinone; PRG, progesterone.

a,b Mean values within a row with unlike superscript letters were significantly different $(P<0.05)$.

Table 7. Effects of dietary pyrroloquinoline quinone (PQQ) supplementation during gestation and lactation on villous height, crypt depth and villous height/ crypt depth $(\mathrm{V} / \mathrm{C})$ in small intestine of weaned rats

(Mean values with their standard errors, $n 6$ )

\begin{tabular}{|c|c|c|c|c|c|c|}
\hline Item & PQQ 0 & PQQ 0.2 & PQQ 0.4 & PQQ 0.8 & PQQ 1.6 & SEM \\
\hline \multicolumn{7}{|l|}{ Duodenum ( $\mu \mathrm{m})$} \\
\hline Villous height & $1827 \cdot 18^{b}$ & $2394.78^{a}$ & $2109 \cdot 35^{a, b}$ & $2174 \cdot 39^{a, b}$ & $2368 \cdot 38^{a}$ & 68.42 \\
\hline Crypt depth & 749.07 & $706 \cdot 32$ & $650 \cdot 65$ & $771 \cdot 18$ & 769.52 & $22 \cdot 35$ \\
\hline $\mathrm{V} / \mathrm{C}$ & 2.44 & 3.39 & 3.24 & 2.82 & 3.01 & 0.15 \\
\hline \multicolumn{7}{|l|}{ Jejunum ( $\mu \mathrm{m})$} \\
\hline Villous height & $1879 \cdot 46^{\mathrm{b}}$ & $1837 \cdot 55^{\mathrm{b}}$ & $1857 \cdot 86^{b}$ & $1945 \cdot 92^{a, b}$ & $2288 \cdot 78^{a}$ & 83.72 \\
\hline Crypt depth & 689.00 & 677.39 & 621.02 & 713.09 & 672.53 & $16 \cdot 15$ \\
\hline $\mathrm{V} / \mathrm{C}$ & 2.72 & 2.71 & 2.99 & $2 \cdot 73$ & 3.40 & 0.12 \\
\hline \multicolumn{7}{|l|}{ Ileum $(\mu \mathrm{m})$} \\
\hline Villous height & $2527 \cdot 11$ & $2216 \cdot 14$ & $2427 \cdot 10$ & $2497 \cdot 10$ & $2625 \cdot 90$ & 71.93 \\
\hline Crypt depth & 763.01 & $736 \cdot 74$ & $785 \cdot 61$ & $668 \cdot 76$ & $703 \cdot 72$ & 24.64 \\
\hline $\mathrm{V} / \mathrm{C}$ & 3.31 & 3.01 & 3.01 & 3.63 & 3.73 & 0.20 \\
\hline
\end{tabular}

${ }^{a, b}$ Mean values within a row with unlike superscript letters were significantly different $(P<0.05)$.

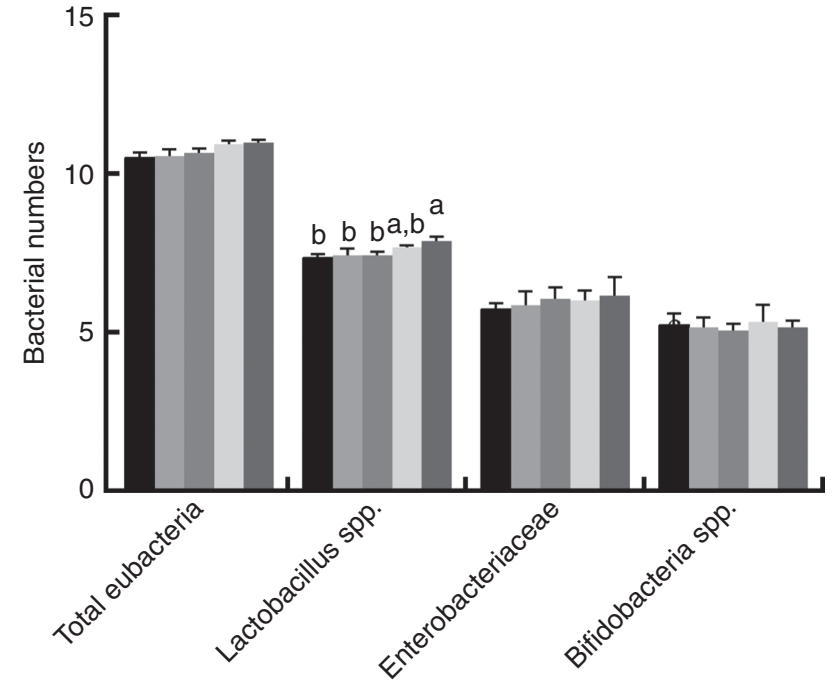

Fig. 2. Effects of dietary pyrroloquinoline quinone (PQQ) disodium supplementation during gestation and lactation of rats on bacterial numbers of weaned rats. The results were reported as log10 16S ribosomal DNA gene copies/g fresh matter. Values are means $(n 6)$, with their standard errors represented by vertical bars. ${ }^{a, b}$ Mean values with unlike letters were significantly different $(P<0.05)$. $\square, \mathrm{PQQ} 0$;, $\mathrm{PQQ} 0.2$;, $\mathrm{PQQ} 0.4$; , PQQ 0.8; , PQQ 1.6.

height/crypt depth $(\mathrm{V} / \mathrm{C})$ in the small intestine of weaned rats are shown in Table 7. Duodenum villous height was significantly higher in the PQQ 0.2 and PQQ 1.6 weaned rat groups $(P<0.05)$. The jejunum villous height increased significantly in a dose-dependent manner in the PQQ 1.6 group of weaned rats $(P<0 \cdot 05)$, from PQQ 0.2 to PQQ $1 \cdot 6$. The small intestine $\mathrm{V} / \mathrm{C}$ had an increasing tendency, but this difference was not significant $(P>0 \cdot 05)$. There were no effects on crypt depth in the small intestine with dietary PQQ $\cdot \mathrm{Na}_{2}$ supplementation during gestation and lactation $(P>0 \cdot 05)$.

\section{Intestinal microflora of weaned rats}

Fig. 2 shows that dietary supplementation with PQQ $\cdot \mathrm{Na}_{2}$ influenced bacterial numbers in the digesta of the caecum in weaned rats on PD 21. There was a significant increase between the PQQ 0 and PQQ 1.6 groups in regard to the number of Lactobacillus spp. in the digesta of the caecum in weaning rats on PD $21(P<0 \cdot 05)$. The numbers of total eubacteria, Enterobacteriaceae and Bifidobacterium spp. exhibited an increasing tendency, with a concomitant increase in dietary PQQ $\cdot \mathrm{Na}_{2}$ concentration supplementation when compared to the PQQ 0 group, but this difference was not significant $(P>0.05)$.

\section{Antioxidant capacity in the small intestine}

The effects of dietary PQQ $\mathrm{Na}_{2}$ supplementation during gestation and lactation on antioxidant capacity in the small intestine of female rats on GD 20 is shown in Fig. 3. On GD 20, the CAT activity in the ileum of female rats was significantly increased by PQQ $\cdot \mathrm{Na}_{2}$ supplementation $(P<0.05)$, and this is the response at all concentrations. Fig. 4 shows that dietary supplementation 

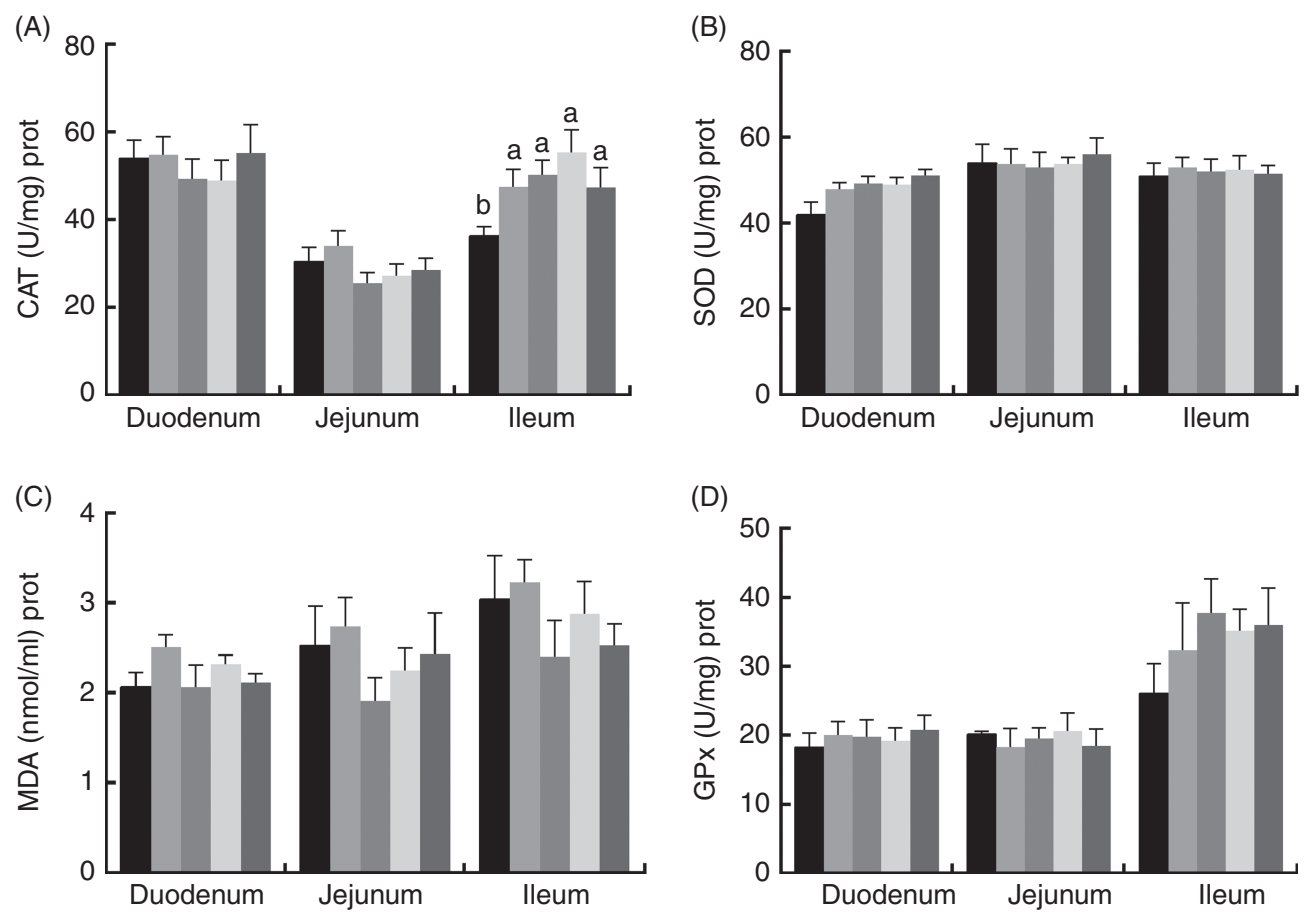

Fig. 3. Effects of dietary pyrroloquinoline quinone $(\mathrm{PQQ})$ disodium supplementation during gestation and lactation of female rats on antioxidant status in small intestine on gestation day 20. (A) Catalase (CAT), (B) superoxide dismutase (SOD), (C) malondialdehyde (MDA) and (D) glutathione peroxidase (GSH-Px). Values are means $(n 6)$, with their standard errors represented by vertical bars. ${ }^{a, b}$ Mean values with unlike letters were significantly different $(P<0.05)$. $\square, P Q Q 0$;,$P Q Q 0.2$; $\square$, $\mathrm{PQQ} 0.4 ;$, PQQ 0.8;, $\mathrm{PQQ} 1.6$.
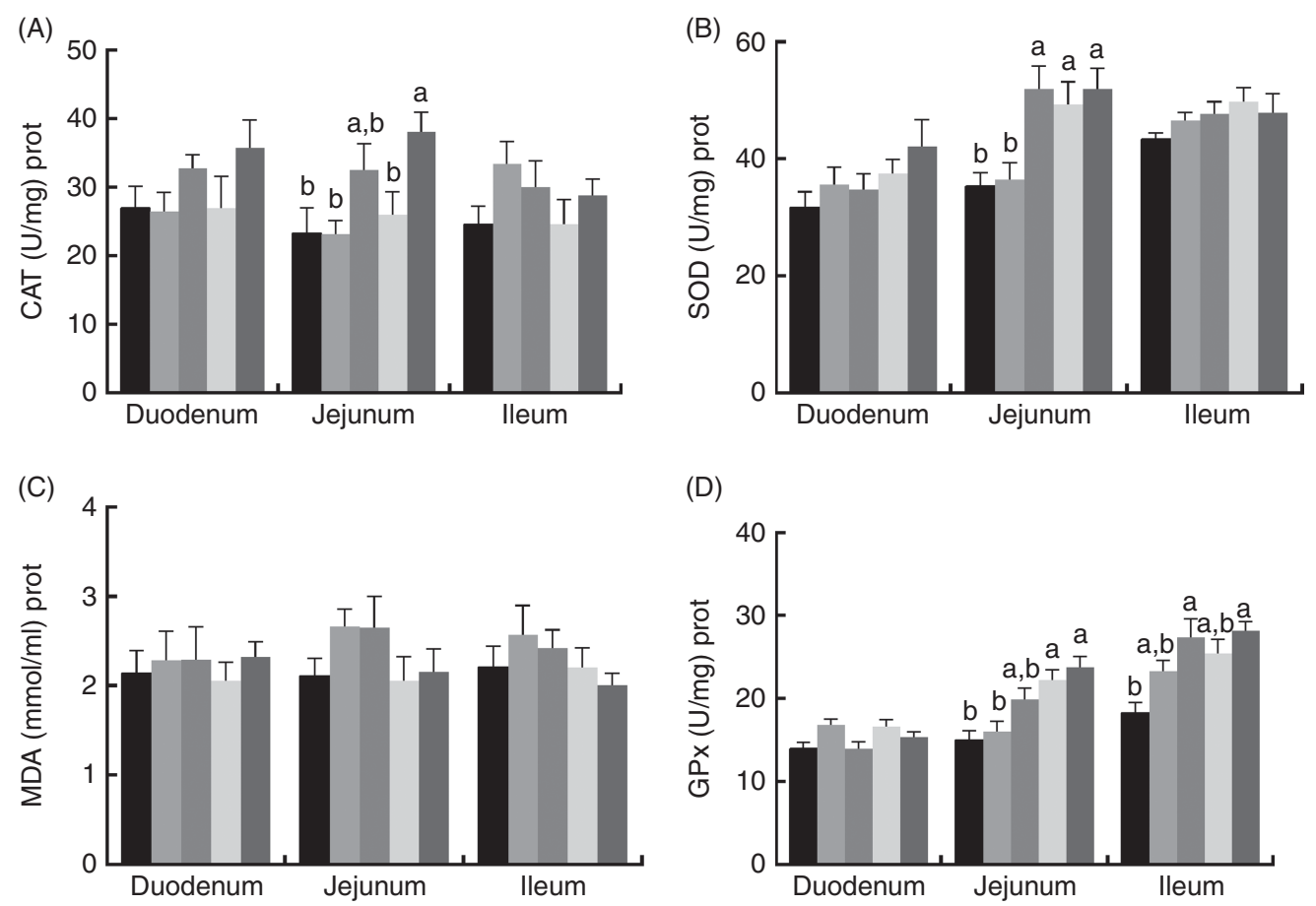

Fig. 4. Effects of dietary pyrroloquinoline quinone (PQQ) disodium supplementation during gestation and lactation of weaned rats on antioxidant status in small intestine. (A) Catalase (CAT), (B) superoxide dismutase (SOD), (C) malondialdehyde (MDA) and (D) glutathione peroxidase (GSH-Px). Values are means ( $n 6)$, with their standard errors represented by vertical bars. ${ }^{a, b}$ Mean values with unlike letters were significantly different $(P<0.05)$. $\square, P Q Q 0 ; \square, P Q Q 0.2 ; \square, P Q Q 0.4 ;$, PQQ 0.8; 1 , PQQ 1.6. 


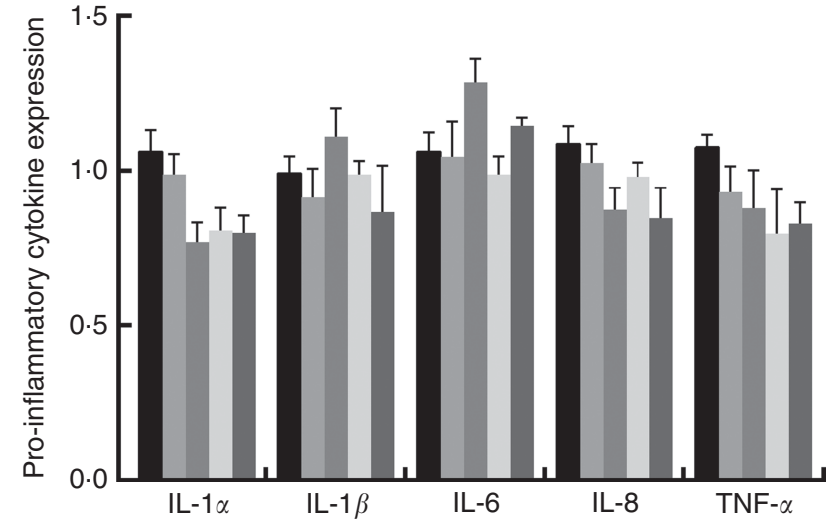

Fig. 5. Effects of dietary pyrroloquinoline quinone (PQQ) disodium supplementation during gestating and lactating rats on the concentrations of cytokines in the jejunal mucosa of weaned rats. $\square, P Q Q 0$; , PQQ 0.2; PQQ 0.4; , PQQ 0.8; , PQQ 1.6.

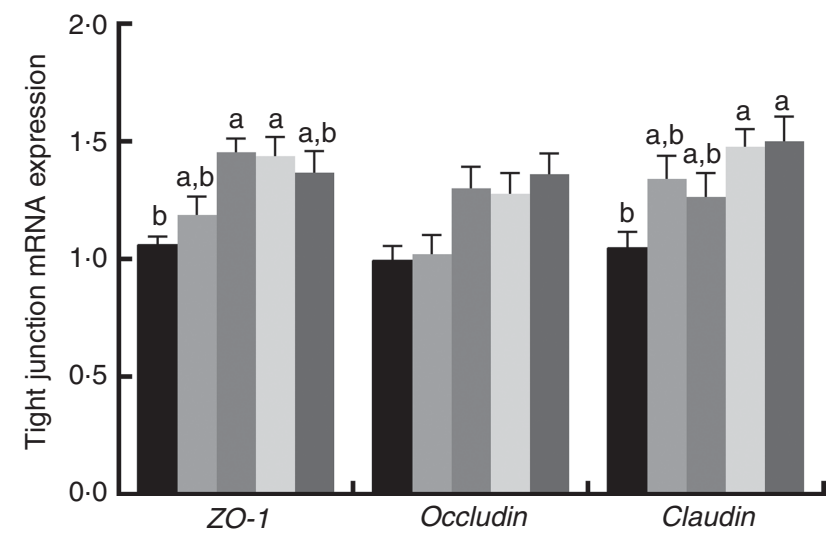

Fig. 6. Effects of dietary pyrroloquinoline quinone (PQQ) disodium supplementation during gestating and lactating rats on tight junction mRNA expression in the jejunal mucosa of rats weaned from their offspring. ZO-1, zonula occludens-1. Values are means $(n 6)$, with their standard errors represented by vertical bars. ${ }^{a, b}$ Mean values with unlike letters were significantly different $(P<0.05)$. $\square, \mathrm{PQQ} 0$; $\square, \mathrm{PQQ} 0.2$;, $\mathrm{PQQ} 0.4$; PQQ 0.8; , PQQ 1.6.

with PQQ $\cdot \mathrm{Na}_{2}$ influenced the antioxidant status in the small intestine in weaned rats on PD 21. PQQ $\cdot \mathrm{Na}_{2}$ dietary supplementation in gestating and lactating rats (PQQ 1.6) increased the CAT activity of the jejunal mucosa of weaned rats on PD 21 $(P<0.05)$. The SOD activity of the jejunal mucosa was significantly increased in the PQQ 0.4 , PQQ 0.8 and PQQ 1.6 groups of weaned rats $(P<0 \cdot 05)$. While PQQ $\cdot \mathrm{Na}_{2}$ (in the PQQ $0 \cdot 4$, PQQ 0.8 and PQQ 1.6 groups) induced a significant increase in GPx activity of the jejunum in weaned rats $(P<0.05)$. In addition, PQQ 0.4 and PQQ 1.6 groups exhibited a significant increase in the GPx activity of the ileum mucosa in weaned rats.

\section{Gene expression of tight junction proteins and concentrations of cytokines in jejunal of weaned rats}

Immune responses in the intestinal mucosa are partly controlled by cytokine release in response to environmental stimuli. We therefore investigated the gene expression of cytokines in the jejunum. The results are shown in Fig. 5. The mRNA expression of pro-inflammatory cytokines including IL- 8, TNF- $\alpha$ and IL- $1 \alpha$ exhibited a reducing tendency, but these differences were not significant $(P>0.05)$. The IL-6 and IL- $\beta$ cytokines were not affected $(P>0 \cdot 05)$ by dietary PQQ $\cdot \mathrm{Na}_{2}$. Fig. 6 shows that dietary supplementation with $\mathrm{PQQ} \cdot \mathrm{Na}_{2}$ influenced the expression of tight junction proteins in the jejunum of weaned rats. The results of the expression of tight junction proteins suggest that dietary supplementation with $\mathrm{PQQ} \cdot \mathrm{Na}_{2}$ in gestating and lactating rats (PQQ 0.4 and PQQ 0.8 groups) increased the expression of zonula occludens-1 (ZO-1) mRNA in the jejunal mucosa of weaned rats $(P<0.05)$. In addition, the expression of claudin mRNA in the jejunal mucosa in the PQQ 0.8 and PQQ 1.6 groups was significantly increased in weaned rats $(P<0.05)$. The expression of occludin mRNA showed an increasing trend with an increase in PQQ $\cdot \mathrm{Na}_{2}$, but this was not significant $(P>0 \cdot 05)$.

\section{Brush border enzymes activities}

There was a significant increase $(P<0.05)$ between PQQ 1.6 and PQQ 0 groups regarding the activities of sucrase in the jejunum of the pregnant rats on GD 20 (Fig. 7(A)). Furthermore, PQQ 0.4 and PQQ 1.6 groups increased $(P<0.05)$ the activities of maltase in the jejunum of the pregnant rats on GD 20 (Fig. 7 (A)). Fig. 7(B) shows the enzyme activities in the jejunum of the weaned rats. PQQ 0.4 and PQQ 1.6 groups had a significant increase $(P<0.05)$ in the activity of sucrase in the jejunum on PD 21 (Fig. 7(B)). The activity of maltase in the jejunum was significantly increased $(P<0.05)$ in the PQQ 0.8 and PQQ 1.6 groups of weaned rats on PD 21, showing dose dependency.

\section{Discussion}

The use of PQQ in nutrition is increasingly being discussed in the literature ${ }^{(8,12)}$. There are several studies that have found beneficial effects of PQQ supplementation on the growth performance or body composition of growing rats ${ }^{(18,19)}$. Jonscher et $a{ }^{(36)}$ reported that PQQ treatment led to a significant increase in placental weight and placental surface area. The major objective of the present study was to investigate the influence of dietary PQQ $\cdot \mathrm{Na}_{2}$ supplementation during gestation and lactation on reproductive performance in SD rats and on antioxidant gene expression in the placenta and the effect of the intestinal barrier functions of their offspring. To our knowledge, this is the first study to examine the effects of dietary PQQ $\cdot \mathrm{Na}_{2}$ supplementation during gestation and lactation in SD rats and to investigate the effect of dietary treatment and PQQ $\cdot \mathrm{Na}_{2}$ during gestation and lactation in female rats on the intestinal barrier functions of their offspring.

Oxidative stress, an imbalance between pro-oxidative and antioxidative forces in biological systems, may cause both lipid and protein oxidation and impair normal cell function, which is considered to be responsible for the initiation or development of pathological processes affecting female reproductive processes $^{(37,38)}$. Studies have reported that lipid peroxidation and oxidative stress are higher during normal pregnancy than 
(A)

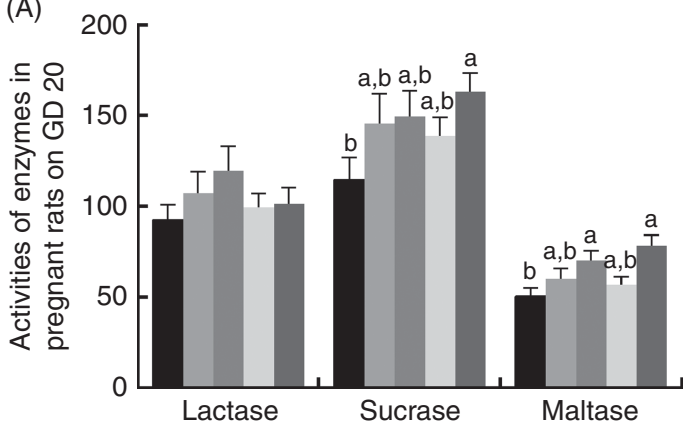

(B)

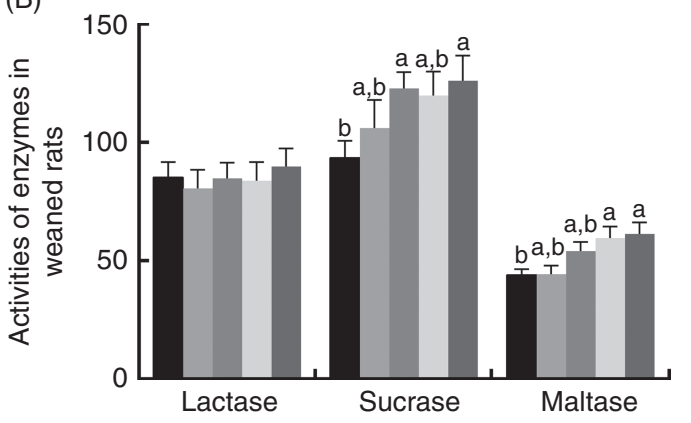

Fig. 7. Effects of dietary pyrroloquinoline quinone (PQQ) disodium supplementation during gestating and lactating rats on brush border enzyme activities in the jejunal. (A) Activities of brush border enzymes in the jejunal of female rats on gestation day (GD) 20; (B) activities of brush border enzymes in the jejunal of weaned rats. Values are means $(n 6)$, with their standard errors represented by vertical bars. ${ }^{\mathrm{a}, \mathrm{b}}$ Mean values with unlike letters were significantly different $(P<0.05)$. $\square$, PQQ 0 ; PQQ 0.2; , PQQ 0.4; , PQQ 0.8; , $\mathrm{PQQ} 1.6$.

during non-pregnancy in women ${ }^{(39)}$. In addition, oxidative stress has been suggested as a causative agent in human and animal pregnancy-related disorders, including embryonic reabsorption, recurrent pregnancy loss, pre-eclampsia, intrauterine growth restriction and fetal death, many of which are predictive of an elevated risk of the metabolic syndrome in postnatal life and may be a common pathway in developmental metabolic programming ${ }^{(40,41)}$. The activity of SOD is known to serve a protective function in the elimination of reactive free radicals, and, therefore, it represents an important antioxidant defence in nearly all cells exposed to oxygen. GSH forms an important part of the non-enzymatic antioxidants ${ }^{(42)}$. Similar to other sulfhydryl-containing products, GSH also has regulatory and protective roles in the body as it establishes the defence line of the body against tissue injury due to chemicals through its reactive oxygen species (ROS) scavenger, cell viability and membrane-stabilising effects ${ }^{(43)}$. In our study, the antioxidant gene expressions of CAT, SOD and Gpx in the placenta were increased $(P<0.05)$ with dietary PQQ $\mathrm{Na}_{2}$ supplementation. The antioxidant enzymes SOD and CAT are considered the firstline defence against ROS. In our study, an increase in CAT and SOD was observed $(P<0.05)$ with dietary PQQ $\cdot \mathrm{Na}_{2}$ supplementation in the placenta. A previous study has demonstrated that SOD activity can be up-regulated by PQQ $\cdot \mathrm{Na}_{2}$ treatment ${ }^{(44)}$, and this is consistent with our study results. GSH is one of the most important molecules in mammalian cells for scavenging ROS. Thiol-containing compounds such as GSH and thioredoxin are oxidised by free radicals and rapidly regenerated $^{(45)}$. GSH is the most abundant endogenously synthesised, thiol-containing, small-molecule tripeptide that can directly scavenge ROS in mammalian cells ${ }^{(46)}$. The mRNA expression levels of GPx2 in the placenta were also increased $(P<0.05)$ with dietary PQQ $\cdot \mathrm{Na}_{2}$ supplementation. PQQ acts as an antioxidant by scavenging $\mathrm{O}_{2}^{-}$and protects mitochondria from oxidative stress-induced damage. Therefore, the number of implanted embryos per litter were significantly increased $(P<0.05)$ with dietary PQQ. $\mathrm{Na}_{2}$ during gestation and lactation at GD 20. The number of viable fetuses per litter and weight of uterine horns with fetuses were increased at $1 \mathrm{~d}$ of the newborn $(P<0.05)$. Glucose and amino acids are the primary energy substrates utilised by the developing fetus and are transported across the placenta by glucose (Slc2a1 and Slc2a3). In our study, the mRNA expression of Slc2a1 and Slc2a3 were increased $(P<0.05)$ with dietary PQQ $\cdot \mathrm{Na}_{2}{ }^{(47)}$. Many nutrient carriers and growth factors and fetal placenta from birth mothers decrease as the dam is exposed to stress. Because the number of implanted embryos per litter was significantly increased $(P<0.05)$ with dietary PQQ $\cdot \mathrm{Na}_{2}$ at GD 20 , more glucose and amino acids were transported across the placenta by $\operatorname{Slc} 2 a 1$ and $\operatorname{Slc} 2 a 3^{(48)}$.

Dietary substances that can alter hormone levels are of concern during pregnancy and are hormone sensitive for both mother and fetus ${ }^{(49)}$. An increased feeding level PRG concentrations of gestation have been reported to be dependent on LH secretion ${ }^{(50,51)}$, an increased $\mathrm{LH}$ secretion could therefore positively influence PRG concentration. The concentrations of PRG and oestrogen during pregnancy are high in mammals. PRG is critical for the establishment and maintenance of pregnancy, as its functions support ovulation and uterine as well as mammary gland development. The ovarian corpus luteum is the major source of PRG during pregnancy ${ }^{(52)}$. Oestrogen not only plays an essential role in the maintenance of pregnancy ${ }^{(53)}$ but also participates in the implantation process and stimulates the development of the mammary gland ${ }^{(54)}$. Generally, oestrogen and PRG perform in synergy. In our study, we observed that the E2, LH and PRG increased significantly $(P<0.05)$ with dietary PQQ $\cdot \mathrm{Na}_{2}$ in the blood plasma on GD 20. E2 and PRG act on the central nervous system, ovary and uterus and are important for ovulation, fertilisation, implantation of embryo, maintenance of pregnancy, mammary gland development and lactation $^{(55)}$. So PQQ $\cdot \mathrm{Na}_{2}$ supplementation significantly improved the serum E2, LH and PRG, which suggested that PQQ $\cdot \mathrm{Na}_{2}$ improved reproductive performance in rats, which in turn is associated with higher levels of hormones.

A maternal effect is a situation where the phenotype of an organism is determined not only by the environment it experiences and its genotype but also by the maternal environment and the genotype. The nutrient environment experienced by the mother is one of the most important factors affecting the growth and development of offspring in addition to heredity. The nutrient environment experienced by the mother can not only change physiological parameters but also affect the growth and development of the offspring by increasing or decreasing its sensitivity to the maternal 
transmission factor. In our study, the results of antioxidant capacity by $\mathrm{PQQ} \cdot \mathrm{Na}_{2}$ in the small intestine were not significant ( $P>0.05$ ) on GD 20 (except for the CAT activity in the ileum). However, dietary supplementation with PQQ $\cdot \mathrm{Na}_{2}$ in gestating and lactating rats (PQQ 1.6 group) increased the CAT activity of the jejunal mucosa of weaned rats on PD $21(P<0 \cdot 05)$. The SOD activity of the jejunal mucosa was significantly increased in the PQQ 0.4 , PQQ 0.8 and PQQ 1.6 groups of weaned rats $(P<0.05)$. PQQ (PQQ 0.4, PQQ 0.8 and PQQ 1.6 groups) also induced a significant increase in GPx activity of the jejunum in weaned rats $(P<0 \cdot 05)$. These results show that there is no significance in the antioxidant capacity of the small intestine by PQQ $\cdot \mathrm{Na}_{2}$ in female rats. However, because of the maternal effect, PQQ can be transported to the offspring through the placenta and milk to improve the antioxidant capacity in the small intestine as a result of maternal supplementation with PQQ $\cdot \mathrm{Na}_{2}$.

The gastrointestinal tract acts as the primary immune organ because it must respond to pathogenic stimuli and maintain resistance to co-immunisation and dietary antigens. Intestinal immunity is also closely related to other intestinal functions. Previous studies have shown that reduced expression of inflammatory cytokine genes may promote a more stable ecosystem and interfere with the growth of certain bacterial populations ${ }^{(56)}$. Accelerated inflammatory cytokine factor overdose production can increase gut mucosal injury partially ${ }^{(57)}$. In a recent study, most of the pro-inflammatory cytokines such as TNF- $\alpha$, IL- $1 \alpha$, IL- $1 \beta$, IL- 6 and IL- 8 induced a pathological opening of the intestinal tight junction barrier and the intestinal epithelium was shown to increase permeability ${ }^{(58)}$. In the present study, our results show that the mRNA expression of pro-inflammatory cytokines including IL-8, TNF- $\alpha$ and IL- $1 \alpha$ exhibited a reducing tendency, which is consistent with that of Steinberg et al. ${ }^{(19)}$. Omata et $a l .{ }^{(59)}$ reported that PQQ is not included in clinically treated parenteral nutrient solutions because it has not been proven to be an essential nutrient for the body. However, in patients receiving parenteral nutrition, the possibility of PQQ supplements preventing gastrointestinal mucosal immune disorders exists ${ }^{(59)}$.

Parenteral nutrition can be used to prevent and reverse malnutrition and to maintain the nutritional status of patients who are unable to receive adequate enteral nutrition. During weaning, the intestinal morphology often undergoes large changes characterised by a decrease in the height of the villi and an increase in the depth of the crypt. This finding suggests that due to nutrient absorption, the surface area present on the villi is small, and the increase in immature fluff formed in the crypt may reduce the overall growth performance of the animal. In the present study, dietary supplementation with PQQ $\cdot \mathrm{Na}_{2}$ on duodenum villous height was significantly higher in weaned rats $(P<0.05)$. The villous height of the jejunum was significantly increased in the PQQ 1.6 group of weaned rats $(P<0.05)$. Variations in both villous height and the ratio of villous height and crypt are good indicators of improved nutrient digestion and absorption capacity of the small intestine. Previous studies have shown that lower villus height and crypt depth is related to microbial challenges and the composition of animal feed ${ }^{(60)}$. Hedemann et al. ${ }^{(61)}$ reported that the increases in villus length can inhibit the growth of many pathogens. The intestinal epithelial layer acts as a barrier to the infiltration of harmful intestinal contents into the bloodstream. In the jejunum, when the microvilli become more sparse and shorter, the permeability of the intestinal epithelial layer increases, the inflammatory response increases and intestinal motor dysfunction increases ${ }^{(62)}$. Therefore, we have further studied the gene expression of tight junction proteins and cytokine concentrations in the jejunum of weaned rats on PD 21. Tight junction proteins (claudin 1, ZO-1 and occludin) have a crucial role in intestinal barrier integrity and permeability by sealing the paracellular space between epithelial cells, thus preventing the paracellular diffusion of intestinal bacteria and other antigens across the epithelium ${ }^{(63)}$. Friedman et al. ${ }^{(64)}$ reported that continuous exposure to PQQ improved the barrier dysfunction. Yin et $a l .{ }^{(65)}$ suggested that the expression of the jejunal tight junction protein $Z O-1$ was significantly higher in pigs with increase in PQQ $\cdot \mathrm{Na}_{2}$. In our study, the results of the expression of tight junction proteins showed that dietary supplementation with PQQ $\cdot \mathrm{Na}_{2}$ increased the expression of $Z O-1$ and claudin mRNA in the jejunal mucosa of weaned rats $(P<0 \cdot 05)$. Proinflammatory cytokines have been shown to down-regulate tight junction protein gene expression ${ }^{(58,66)}$ through the dysregulation of tight junction proteins, resulting in an increase in intestinal permeability ${ }^{(67)}$. This is part of the reason for increased higher expression of ZO-1 and claudin mRNA in weaned female rats supplemented with PQQ $\mathrm{Na}_{2}$. Furthermore, the high concentration of PQQ in the offspring of female rats supplemented with PQQ can exert an antioxidant property, decreasing lipid peroxidation and ROS formation, possibly resulting in the increased expression of $\mathrm{ZO}-1$ and claudin mRNA. The present study indicates that supplementation with PQQ $\cdot \mathrm{Na}_{2}$ in female rats could enhance intestinal barrier integrity by up-regulating the tight junction protein mRNA in weaned rats.

The activity of brush border enzymes (such as lactase, sucrase and maltase) is closely related to the digestion of nutrients. Disaccharides (e.g. sucrose, maltose and lactose) can be hydrolysed by sucrase, maltase and lactase to the corresponding monosaccharide to be absorbed by the small intestine ${ }^{(68)}$. Disaccharides can only be absorbed by the disaccharidase of the small intestine. Improving disaccharide activity in the small intestine provides sustained energy storage that promotes carbohydrate degradation and also growth and development. The disaccharidase (i.e. brush edge enzyme) released by epithelial cells after shedding is determined by the height and maturation of chorionic cells ${ }^{(69)}$. In the present study, there was a significant effect $(P<0.05)$ of increasing PQQ $\cdot \mathrm{Na}_{2}$ supplementation on the activities of sucrase and maltase in the jejunum of the pregnant rats on GD 20. There was also a significant effect $(P<0.05)$ of increasing PQQ. $\mathrm{Na}_{2}$ supplementation on the activities of sucrase and maltase in the jejunum of the weaned rats on PD 21. These results indicate that PQQ can improve the activities of sucrase and maltase. Simultaneously, this also indicates that PQQ can be passed through the mother to improve the activities of sucrase and maltase in weaned rats. One of the most important beneficial effects of the primary plexus is the creation of a barrier. Barriers are needed, as exogenous pathogens can cause colonisation of the digestive 
tract to be more difficult and may cause a disease called microbial colonisation resistance ${ }^{(70)}$. Therefore, one aim of the present study was to detect whether the PQQ diet of gestating and lactating female rats can affect the composition of the intestinal flora in their offspring. As the results show, dietary supplementation with PQQ $\mathrm{Na}_{2}$ increased the number of Lactobacillus spp. in the digesta of the caecum in weaned rats.

\section{Conclusions}

In conclusion, our results have shown that dietary $1.6 \mathrm{mg} / \mathrm{kg}$ PQQ $\cdot \mathrm{Na}_{2}$ supplementation during gestation and lactation of female rats can significantly increase the number of viable fetuses per litter, born alive litter weight and the mRNA expression levels of CAT, GPX2 and SOD1 in the placenta, thereby increasing the reproductive performance. The duodenum villous height, jejunum villous height, the activities of maltase and sucrase, the number of Lactobacillus spp. and the expression of $Z O-1$ and claudin mRNA were significantly increased by $1.6 \mathrm{mg} / \mathrm{kg}$ PQQ $\cdot \mathrm{Na}_{2}$ supplementation. It suggested that PQQ can improve intestinal health by enhancing the intestinal morphology, tight junction function and improving the antioxidant status. The dietary supplementation of $1.6 \mathrm{mg} / \mathrm{kg}$ PQQ $\cdot \mathrm{Na}_{2}$ is the best functional dose to improve reproductive performance of female rats and the intestinal barrier functions in the progeny based on the results from the present study.

\section{Acknowledgements}

The authors wish to acknowledgement the assistance of Yinguo Li, Chunliang Zhao and Xiaoyu Li.

This work was supported by the National Key Research and Development Plan of China (2016YFD0501207), the China Agriculture Research System (CARS-36). The funders had no role in the design, analysis or writing of this manuscript.

All authors participated in the development of the study concept and design. B. Z., W. Y. and H. Z. were responsible for the execution of the study. B. W., S. H. and Q. M. were involved in the animal experiments, analysis and data collection. Q. M. and Z. C. were responsible for the statistical analysis. B. Z. wrote the draft of the manuscript. Q. M., A. S. and Z. C. reviewed and revised the manuscript.

None of the authors has any conflicts of interest to declare.

\section{References}

1. Ahmed N \& Shahab S (2010) Involvement of bacterial pyrroloquinoline in plant growth promotion: a novel discovery. World Appl Sci J 8, 57-61.

2. Adachi O (2007) Biooxidation with PQQ- and FAD-dependent dehydrogenases. In Modern Biooxidation: Enzymes, Reactions and Applications [RD Schmid and VB Urlacher, editors]. Weinheim, Germany: Wiley.

3. Alkasrawi M, Popescu IC, Mattiasson B, et al. (1999) A redox hydrogel integrated PQQ-glucose dehydrogenase based glucose electrode. Anal Commun 36, 395-398.

4. Naveed M, Tariq K, Sadia H, et al. (2016) The life history of pyrroloquinoline quinone (PQQ): a versatile molecule with novel impacts on living systems. Mol Biol 1, 29-46.
5. Rucker R, Stites T, Steinberg F, et al. (2000) Physiological Importance of Pyrroloquinoline Quinone. Basel: Birkhäuser.

6. Kasahara T \& Kato T (2003) Nutritional biochemistry: a new redox-cofactor vitamin for mammals. Nature 422, 832.

7. Misra HS, Rajpurohit YS \& Khairnar NP (2012) Pyrroloquinoline-quinone and its versatile roles in biological processes. J Biosci 37, 313-325.

8. Samuel KG, Zhang HJ, Wang J, et al. (2015) Effects of dietary pyrroloquinoline quinone disodium on growth performance, carcass yield and antioxidant status of broiler chicks. Animal 9. 409-416.

9. Noji N, Nakamura T, Kitahata N, et al. (2007) Simple and sensitive method for pyrroloquinoline quinone (PQQ) analysis in various foods using liquid chromatography/electrospray-ionization tandem mass spectrometry. J Agric Food Chem 55, 7258-7263.

10. Bishop A, Gallop PM \& Karnovsky ML (1998) Pyrroloquinoline quinone: a novel vitamin? Nutr Rev 56, 287-293.

11. Tsuchida T, Yasuyama T, Higuchi K, et al. (1993) The protective effect of pyrroloquinoline quinone and its derivatives against carbon tetrachloride-induced liver injury of rats. J Gastroenterol Hepatol 8, 342-347.

12. Wang J, Zhang HJ, Xu L, et al. (2016) Dietary supplementation of pyrroloquinoline quinone disodium protects against oxidative stress and liver damage in laying hens fed an oxidized sunflower oil-added diet. Animal 10, 1129-1136.

13. Mitchell AE, Jones AD, Mercer RS, et al. (1999) Characterization of pyrroloquinoline quinone amino acid derivatives by electrospray ionization mass spectrometry and detection in human milk. Anal Biochem 269, 317-325.

14. Kumazawa T, Sato K, Seno H, et al. (1995) Levels of pyrroloquinoline quinone in various foods. Biochem J 307, 331-333.

15. Ameyama M, Nonobe M, Shinagawa E, et al. (1985) Method of enzymatic determination of pyrroloquinoline quinone. Anal Biochem 151, 263-267.

16. Bergethon PR (1990) Amperometric electrochemical detection of pyrroloquinoline quinone in high-performance liquid chromatography. Anal Biochem 186, 324-327.

17. Felton LM \& Anthony C (2005) Biochemistry: role of PQQ as a mammalian enzyme cofactor? Nature 433, 11-12.

18. Steinberg F, Stites TE, Anderson P, et al. (2003) Pyrroloquinoline quinone improves growth and reproductive performance in mice fed chemically defined diets. Exp Biol Med 228, 160-166.

19. Steinberg FM, Gershwin ME \& Rucker RB (1994) Dietary pyrroloquinoline quinone: growth and immune response in BALB/c mice. J Nutr 124, 744-753.

20. Steinberg F, Stites TE, Anderson P, et al. (2003) Pyrroloquinoline quinone improves growth and reproductive performance in mice fed chemically defined diets. Exp Biol Med 228, 160-166.

21. Government of Canada (2012) Health Products, Food Branch NHPD Natural Health Products - Drugs and Health Products Main Page. Health Canada. https://www.canada.ca/en/healthcanada/corporate/about-health-canada/branches-agencies/ health-products-food-branch/natural-non-prescription-healthproducts-directorate.html

22. Wang J, Zhang HJ, Samuel KG, et al. (2015) Effects of dietary pyrroloquinoline quinone disodium on growth, carcass characteristics, redox status, and mitochondria metabolism in broilers. Poult Sci 94, 215-225.

23. Kuang W, Liu Y, Qiang LI, et al. (2017) Effects of PQQ on yield composition and main agronomic characters of rice. Hunan Agric Sci 12, 40-42.

24. Akagawa M, Nakano M \& Ikemoto K (2015) Recent progress in studies on the health benefits of pyrroloquinoline quinone. J Agric Chem Soc Japan 80, 13-22. 
25. Wen-Min HU, Lin-Zi LI, Zhang L, et al. (2016) Effects of PQQ on serum lipid and glucose levels, liver function and lipid peroxidation in hyperlipidemia rats. Chinese Prevent Med 17, 23-27.

26. Zhang Y, Jia Z, Yin S, et al. (2014) Toxic effects of maternal zearalenone exposure on uterine capacity and fetal development in gestation rats. Reprod Sci 21, 743-753.

27. Rongzhu L, Suhua W, Guangwei X, et al. (2009) Effects of acrylonitrile on antioxidant status of different brain regions in rats. Neurochem Int 55, 552-557.

28. Elstner EF \& Heupel A (1976) Inhibition of nitrite formation from hydroxylammoniumchloride: a simple assay for superoxide dismutase. Anal Biochem 70, 616-620.

29. Sedlak J \& Lindsay RH (1968) Estimation of total, proteinbound, and nonprotein sulfhydryl groups in tissue with Ellman's reagent. Anal Biochem 25, 192-205.

30. Aebi H (1984) Catalase in vitro. Methods Enzymol 105 , 121-126.

31. Mao X, Lv M, Yu B, et al. (2015) The effect of dietary tryptophan levels on oxidative stress of liver induced by diquat in weaned piglets. J Anim Sci Biotechnol 5, 49.

32. Che L, Xuan Y, Hu L, et al. (2014) Effect of postnatal nutrition restriction on the oxidative status of neonates with intrauterine growth restriction in a pig model. Neonatology 107, 93-99.

33. Bartosch S, Fite A, Macfarlane GT, et al. (2004) Characterization of bacterial communities in feces from healthy elderly volunteers and hospitalized elderly patients by using real-time PCR and effects of antibiotic treatment on the fecal microbiota. Appl Environ Microbiol 70, 3575-3581.

34. Rinttilä T, Kassinen A, Malinen E, et al. (2010) Development of an extensive set of 16S rDNA-targeted primers for quantification of pathogenic and indigenous bacteria in faecal samples by real-time PCR. J Appl Microbiol 97, 1166-1177.

35. Livak KJ \& Schmittgen TD (2001) Analysis of relative gene expression data using real-time quantitative PCR and the 2( - delta delta $C(\mathrm{~T}))$ method. Methods 25, 402-408.

36. Jonscher KR, Stewart MS, Alfonso-Garcia A, et al. (2017) Early PQQ supplementation has persistent long-term protective effects on developmental programming of hepatic lipotoxicity and inflammation in obese mice. FASEB J 31, 1434-1448.

37. Finkel T (2003) Oxidant signals and oxidative stress. Curr Opin Cell Biol 15, 247-254.

38. Serdar Z, Gür E, Colakoethullarý M, et al. (2003) Lipid and protein oxidation and antioxidant function in women with mild and severe preeclampsia. Arch Gynecol Obstet 268, 19-25.

39. Mihu D, Sabău L, Costin N, et al. (2012) Implications of maternal systemic oxidative stress in normal pregnancy and in pregnancy complicated by preeclampsia. J Matern Fetal Neonatal Med 25, 944-951.

40. Pereira AC \& Martel F (2014) Oxidative stress in pregnancy and fertility pathologies. Cell Biol Toxicol 30, 301-312.

41. Sánchez-Aranguren LC, Prada CE, Riaño-Medina CE, et al. (2014) Endothelial dysfunction and preeclampsia: role of oxidative stress. Front Physiol 5, 372.

42. Cheung CC, Zheng GJ, Li AM, et al. (2001) Relationships between tissue concentrations of polycyclic aromatic hydrocarbons and antioxidative responses of marine mussels, Perna viridis. Aquat Toxicol 52, 189-203.

43. Szabó S (1984) Role of sulfhydryls and early vascular lesions in gastric mucosal injury. Acta Physiol Hung 64, 203-214

44. Zhang Q, Ding M, Gao XR, et al. (2012) Pyrroloquinoline quinone rescues hippocampal neurons from glutamateinduced cell death through activation of Nrf2 and upregulation of antioxidant genes. Genet Mol Res 11, 2652-2664.

45. Yang YC, Lii CK, Lin AH, et al. (2011) Induction of glutathione synthesis and heme oxygenase 1 by the flavonoids butein and phloretin is mediated through the ERK/Nrf2 pathway and protects against oxidative stress. Free Radic Biol Med $\mathbf{5 1}$, 2073-2081.

46. Meister A \& Anderson ME (1983) Glutathione. Annu Rev Biochem 52, 711-760.

47. Briffa JF, Hosseini SS, Tran M, et al. (2017) Maternal growth restriction and stress exposure in rats differentially alters expression of components of the placental glucocorticoid barrier and nutrient transporters. Placenta 59, 30-38.

48. Robertson AF \& Karp WB (1976) Placental transport of nutrients. South Med J 69, 1358-1362.

49. Pasqualini JR, Kincl FA \& Sumida C (1991) The binding of hormones in maternal and fetal biological fluids. In Hormones and the Fetus, pp. 1-50. Oxford: Pergamon.

50. Peltoniemi OAT, Easton BG, Love RJ, et al. (1995) Effect of chronic treatment with a GnRH agonist (goserelin) on LH secretion and early pregnancy in gilts. Anim Reprod Sci 40, 121-133.

51. Tast A, Love RJ, Clarke IJ, et al. (2000) Effects of active and passive gonadotrophin-releasing hormone immunization on recognition and establishment of pregnancy in pigs. Reprod Fertil Dev 12, 277-282.

52. Petra A, Hansen PJ, Biserka MJ, et al. (2010) Progesterone during pregnancy: endocrine-immune cross talk in mammalian species and the role of stress. Am J Reprod Immunol 58, 268-279.

53. Albrecht ED, Aberdeen GW \& Pepe GJ (2000) The role of estrogen in the maintenance of primate pregnancy. Am J Obstet Gynecol 182, 432-438.

54. Topper YJ (1970) Multiple hormone interactions in the development of mammary gland in vitro. Recent Prog Horm Res 26, 287-308.

55. Ahmed HM, Yeh JY, Tang YC, et al. (2014) Molecular screening of Chinese medicinal plants for progestogenic and anti-progestogenic activity. J Biosci 39, 453-461.

56. Walsh AM, Sweeney T, O'Shea CJ, et al. (2013) Effect of dietary laminarin and fucoidan on selected microbiota, intestinal morphology and immune status of the newly weaned pig. Br J Nutr 110, 1630-1638.

57. Liu Y, Huang J, Hou Y, et al. (2008) Dietary arginine supplementation alleviates intestinal mucosal disruption induced by Escherichia coli lipopolysaccharide in weaned pigs. $\mathrm{BrJ}$ Nutr 100, 552-560.

58. Alsadi R, Boivin M \& Ma T (2009) Mechanism of cytokine modulation of epithelial tight junction barrier. Front Biosci (Landmark Ed) 14, 2765-2778.

59. Omata J, Fukatsu K, Murakoshi S, et al. (2011) Influence of adding pyrroloquinoline quinone to parenteral nutrition on gutassociated lymphoid tissue. JPEN J Parenter Enteral Nutr 35, 616-624.

60. Sayan H, Assavacheep P, Angkanaporn K, et al. (2018) Effect of Lactobacillus salivarius on growth performance, diarrhea incidence, fecal bacterial population and intestinal morphology of suckling pigs challenged with $\mathrm{F} 4+$ enterotoxigenic Escherichia coli. Asian-Australas J Anim Sci 31, 1308-1314.

61. Hedemann MS, Eskildsen M, Laerke HN, et al. (2006) Intestinal morphology and enzymatic activity in newly weaned pigs fed contrasting fiber concentrations and fiber properties. J Anim Sci 84, 1375-1386.

62. Collins SM (2001) Stress and the gastrointestinal tract IV. Modulation of intestinal inflammation by stress: basic mechanisms and clinical relevance. Am J Physiol Gastrointest Liver Physiol 280, G315-G318.

63. Ulluwishewa D, Anderson RC, Mcnabb WC, et al. (2011) Regulation of tight junction permeability by intestinal bacteria and dietary components. J Nutr 141, 769-776.

64. Friedman JE, Dobrinskikh E, Alfonso-Garcia A, et al. (2018) Pyrroloquinoline quinone prevents developmental programming of microbial dysbiosis and macrophage polarization to 
attenuate liver fibrosis in offspring of obese mice. Hepatol Commun 2, 313-328.

65. Yin X, Ming D, Bai L, et al. (2019) Effects of pyrroloquinoline quinone supplementation on growth performance and small intestine characteristics in weaned pigs. J Anim Sci 97, 246-256.

66. Chen H, Mao X, He J, et al. (2013) Dietary fibre affects intestinal mucosal barrier function and regulates intestinal bacteria in weaning piglets. Br J Nutr 110, 1837-1848.

67. Berin MC, Yang PC, Ciok L, et al. (1999) Role for IL-4 in macromolecular transport across human intestinal epithelium. Am J Physiol 276, 1046-1052.
68. Pappenheimer JR (1993) On the coupling of membrane digestion with intestinal absorption of sugars and amino acids. Am J Physiol 265, 409-417.

69. Chen Q, Zhang H, Zheng Y, et al. (2013) Effects of enzymatically hydrolyzed blood cells on growth performance and intestinal characteristics of newly weaned piglets. Livest Sci 157, 514-519.

70. Brassart D \& Schiffrin EJ (1997) The use of probiotics to reinforce mucosal defence mechanisms. Trends Food Sci Technol 8, 321-326. 